\title{
Peningkatan Pengetahuan dan Keterampilan Manajemen Pada Pelaku UMKM Desa Balesari Kabupaten Magelang
}

\author{
Hanung Eka Atmaja*1, Budi Hartono ${ }^{2}$, Khairul Ikhwan ${ }^{3}$ \\ 1,2,3Program Studi Manajemen, Fakultas Ekonomi, Universitas Tidar \\ *e-mail: hanung.ekaatmaja@untidar.ac.id ${ }^{1}$, hartono.budi@untidar.ac.id², khairulikhwan@untidar.ac.id ${ }^{3}$
}

\begin{abstract}
The community service program carried out in Balesari Village, Windusari District, Magelang Regency, aims to solve mismanagement problems that occur in terms of financial administration, marketing, and human resources. Preliminary observations have been made before, which found that MSMEs in this village still receive minimal guidance in the form of small business management. By knowing the mapping of constraints or problems experienced by MSME actors, it is hoped that they can obtain accurate training materials so that these MSMEs can develop forward and encourage the economy of the surrounding community. The method used is the tutorial and discussion extension method. The material presented is about the basics of management science in business. MSMEs require good knowledge of human resource management, marketing management, and financial management for the progress of their business. MSME owners or managers are expected to have skills in managing their human resources, as well as the ability to manage facilities and infrastructure in their businesses. If MSME managers have good management knowledge, it will make it easier for their business to continue to develop and be adaptive in facing all the demands of changing times. Therefore, this community service is carried out by assisting related partners to develop their business and to be able to compete with other MSMEs. The flow of activities, namely the delivery of material, training, and assistance on the basics of management science. As a result of this dedication, the partners who received admitted aid that they had a better understanding of how to design effective and efficient marketing strategies, how to manage finances in a simple manner, and a little understanding of how to design suitable human resource needs.
\end{abstract}

Keywords: MSMEs, management, marketing, finance, human resources, management

\begin{abstract}
Program kemitraan kepada masyarakat yang laksanakan di Desa Balesari, Kecamatan Windusari, Kabupaten Magelang, neniliki tujuan untuk menyelesaikan berbagai permasalahan yang terjadi baik dari segi administrasi keuangan, pemasaran, dan sumber daya manusia. Observasi pendahuluan telah kami lakukan sebelumnya yang menemukan bahwa UMKM di desa ini masih minim mendapat pembinaan yang bersifat pengelolaan manajemen bisnis kecil. Hasil pemetaan terhadap kendala yang dialami oleh para pelaku UMKM, harapannya mereka dapat memperoleh materi pelatihan yang tepat agar kompetensi para pengusaha UMKM meningkat sehingga dapat mendorong perekonomian masyarakat. Metode penyuluhan tutorial dan diskusi dipilih sebagai metode pengabdian ini. Materi yang disampaikan adalah dasar-dasar pengelolaan bisnis. UMKM membutuhkan pengetahuan tentang manajemen pemasaran, manajemen sumber daya manusia, maupun manajemen keuangan yang baik demi kemajuan usahanya. Pemilik atau pengelola UMKM diharapkan memiliki kecakapan dalam mengelola sumber daya manusianya, maupun kemampuan mengelola sarana dan prasarana di bisnis yang mereka miliki. Pengelola UMKM memiliki pengetahuan manajemen yang baik akan memudahkan usahanya untuk terus tumbuh dan adaptif dalam menghadapi segala tuntutan perubahan jaman. Oleh karena itu, pengabdian kepada masyarakat ini dilakukan dengan cara mendampingi mitra terkait untuk mengembangkan usahanya dan agar mampu bersaing dengan UMKM lainnya. Alur kegiatan yaitu penyampaian materi, pelatihan, dan pendampingan tentang dasardasar ilmu manajemen. Hasil dari pengabdian ini, mitra yang mendapatkan pendampingan mengaku menjadi lebih paham bagaimana merancang strategi pemasaran yang efektif dan efisien, bagaimana mengelola keuangan secara sederhana, dan sedikit memahami bagaimana merancang kebutuhan sumber daya manusia yang baik.
\end{abstract}

Keywords: UMKM, manajemen, pemasaran, keuangan, SDM, pengelolaan

\section{PENDAHULUAN}

Universitas Tidar memiliki Desa Binaan yaitu Desa Balesari, Kecamatan Windusari, Kabupaten Magelang. Perekonomian Desa Balesari digerakkan oleh UMKM (usaha mikro kecil 
menengah) yang sebagian besar merupakan pelaku home industry. UMKM yang ada tersebut hanya mampu menyerap sedikit tenaga kerja. UMKM tersebut memproduksi dalam jumlah kecil untuk memenuhi kebutuhan rumah tangga saja. Peningkatan perekonomian daerah tersebut masih menjadi pekerjaan rumah yang harus direnungkan bersama antara akademisi, perangkat desa, dan tentunya dukungan masyarakat.

Para pelaku UMKM di Desa Balesari banyak yang bergerak di sektor olahan makanan ringan diantaranya keripik, pangsit, dan kopi. UMKM Balesari memiliki potensi besar sebagai salah satu produsen hasil perkebunan rakyat dan makanan olahan di Kabupaten Magelang. Dengan prospek usaha yang bagus dan sumber daya alam yang mendukung, setidaknya Desa ini bisa menjadi pelopor sebagai desa kemandirian anggaran. Namun, banyak potensi yang belum dikelola dengan baik. Salah satunya, terkait pengetahuan dasar bagaimana mengelola bisnis yang baik. Oleh karena itu, UMKM Balesari tersebut dapat berkembang dan adaptif menghadapi tantangan bisnis apabila adanya peningkatan pengetahuan mengenai dasar-dasar ilmu manajemen, khususnya dalam manajemen sumber daya manusia, manajemen keuangan, dan manajemen pemasaran.

Fokus dalam program pengabdian ini yaitu membantu UMKM Desa Balesari yang bergerak pada sektor pengolahan makanan ringan untuk dapat merencanakan bisnis, memasarkan, mengadiministrasikan keuangan, dan menganalisis kebutuhan tenaga kerja secara lebih efektif. Keberhasilan pengembangan UMKM ditentukan oleh faktor-faktor seperti mesin, permodalan, peralatan, sumber daya manusia (SDM), pengelolaan usaha, ketersediaan bahan baku, pemasaran, dan informasi agar bisa melakukan akses pasar (Bismala, 2016). Kompetensi SDM yang bekerja di UMKM pada umumnya masih sangat rendah. Hal ini dikarenakan pelatihan dan pendidikan formal yang kurang memadai. hal ini ditunjukkan dengan masih rendahnya kualitas produk, terbatasnya kemampuan untuk mengembangkan produk-produk baru, lambannya penerapan teknologi, dan lemahnya pengelolaan usaha.

UMKM biasanya dijalankan bukan dengan perencanaan yang matang. Pemilik usaha biasanya terdesak akan kebutuhan ekonomi sehingga pemilik UMKM tidak memiliki kompetensi yang cukup untuk menjalankan dan mengembangkan usahanya (Masnita, 2020). UMKM yang memiliki keunggulan kompetitif mampu memanfaatkan teknologi secara optimal, kualitas SDM yang baik, mampu meningkatkan kualitas produk, mampu melakukan efisiensi dan meningkatkan produktivitas, memiliki akses promosi yang luas, sumber daya modal yang memadai, memiliki jaringan bisnis yang luas, memiliki sistem manajemen kualitas yang terstruktur, dan memiliki jiwa kewirusahaan (Tambunan 2002).

Melakukan pengelolaan terhadap UMKM diperlukan orang yang berani mengambil risiko, kreatitivitas yang tinggi, rasa tidak cepat menyerah, dan selalu berusaha menemukan alternatif baru untuk meningkatkan kinerja (Bhuvaneswari dkk., 2013). UMKM desa Balesari memiliki modal yang cukup untuk menjadi besar dan memiliki daya saing jika memiliki kemampuan manajemen yang solid. Untuk menuju ke sana, tim penulis berupaya meningkatkan keterampilan mereka dengan cara pelaku UMKM Balesari diberikan materi mengenai pengantar manajemen, manajemen pemasaran, manajemen keuangan, dan manajemen sumber daya manusia,.

Tim penulis juga menyampaikan pelatihan pembuatan perencanaan bisnis (business plan) dan pembuatan laporan keuangan kepada pelaku UMKM. Pelatihan ini diberikan dengan tujuan mempermudah pelaku UMKM Balesari dalam membuat sasaran bisnis usahanya. Dengan tersampaikannya pelatihan ini diharapkan para pelaku UMKM dapat bersaing dengan UMKM sejenis. Dalam pelaksanaan pengabdian masyarakat ini UMKM Balesari yang merupakan mitra universitas penulis bekerja, lebih banyak melakukan perbaikan sistem manajemen dan pengelolaan usaha yang lebih baik. 


\section{METODE}

Penulis melakukan pelaksanaan Pengabdian Kepada Masyarakat dengan menggunakan metode tutorial, penyuluhan, dan diskusi. Langkah-langkah dalam melaksanakan pengabdian kepada masyarakat ini adalah sebagai berikut:

a. Langkah 1 (Metode Penyuluhan):

Masyarakat dijelaskan cara membuat business plan (perencanaan bisnis) yang baik dengan cara memberikan materi mengenai manajemen beserta pengetahuan dalam mengelola pembukuan. Tujuan Langkah ini adalah menambah wawasan dan pengetahuan manajemen bagi pemilik UMKM Balesari. Materi penyuluhan tersebut disampaikan dengan cara ceramah dan tanya jawab kepada masyarakat.

b. Langkah 2 (Metode Tutorial):

Masyarakat pelaku UMKM dijelaskan mengenai materi bagaimana cara membuat perancanaan bisnis dan membuat laporan keuangan. Langkah ini bertujuan memberikan keterampilan tentang cara membuat perencanaan bisnis dan laporan keuangan. Materi pembuatan perencanaan bisnis dan laporan keuangan disampaikan dalam bentuk penjelasan dan praktek langsung serta adanya tanya jawab.

c. Langkah 3 (Metode Diskusi):

Masyarakat pelaku UMKM didorong dan dipersilahkan untuk mendiskusikan permasalahan yang mereka hadapi terutama yang berkaitan dengan strategi usaha, kewirausahaan, manajemen SDM, pemasaran, dan manajemen keuangan, dan cara membuat laporan keuangan.

Evaluasi pelaksanaan program dan upaya keberlanjutan program ini dilakukan dengan pengamatan secara kontinu, serta dikatakan berhasil jika UMKM mampu berinovasi, meningkatkan hasil penjualan, dan mendapatkan sumber permodalan. Untuk selanjutnya UMKM diharapkan dapat terus mengembangkan usahanya sehingga omzet yang dimiliki UMKM akan semakin besar.

\section{HASIL DAN PEMBAHASAN}

Secara umum, pelaku UMKM di Desa Balesari sebelum mendapatkan materi pengabdian kepada masyarakat belum menerapkan manajemen secara konsisten. Namun, setelah mendapatkan pelatihan terdapat tiga poin utama yang diutarakan oleh beberapa peserta pelatihan. Pertama, peserta UMKM di Desa Balesari mempunyai gambaran cara membuat perencanaan bisnis yang baik. Hal ini dilakukan dengan cara meningkatkan pengetahuan manajemen peserta dengan pengetahuan dalam mengelola pembukuan. Kedua, peserta UMKM di Desa Balesari mengetahui cara membuat business plan dan membuat laporan keuangan. Ketiga, peserta UMKM di Desa Balesari mengenal manajemen strategik, kewirausahaan, manajemen SDM, keuangan, dan manajemen pemasaran, dan membuat laporan keuangan yang baik dan benar.

Para peserta menyadari bahwa berbagai aspek pengelolaan bisnis merupakan landasan untuk melakukan pengelolaan usaha yang baik. Ukuran usaha yang kecil tidak bisa dijadikan alasan oleh pelaku UKM Desa Balesari untuk berhenti melakukan perbaikan manajemen secara berkelanjutan agar dapat mencapai kesuksesan berbisnis. Peserta juga menyadari bahwa melakukan evaluasi usaha secara berkala merupakan hal yang penting agar mengetahui perkembangan usahanya sendiri.

Secara singkat, hasil dan pembahasan dari program kemitraan kepada masyarakat yang dilakukan oleh penulis dan tim, dijabarkan dalam Tabel 1. 
Tabel 1. Evaluasi Hasi Program

\begin{tabular}{|c|c|c|c|}
\hline Target Program & $\begin{array}{l}\text { Ketercapaian } \\
\text { Program }\end{array}$ & $\begin{array}{c}\text { Perubahan } \\
\text { Mindset Peserta }\end{array}$ & Upaya Keberlanjutan \\
\hline $\begin{array}{l}\text { Peserta mampu } \\
\text { memahami dasar } \\
\text { ilmu Manajemen } \\
\text { Pemasaran }\end{array}$ & Tercapai & $\mathrm{Ya}$ & $\begin{array}{l}\text { Memantau akun e-commerce, sosial } \\
\text { media, dan distribusi produk yang } \\
\text { para peserta sudah terapkan, setelah } \\
\text { itu, penulis dan tim memberikan } \\
\text { masukan jika ada yang kurang tepat. }\end{array}$ \\
\hline $\begin{array}{l}\text { Peserta mampu } \\
\text { memahami dasar } \\
\text { ilmu Manajemen } \\
\text { Keuangan }\end{array}$ & Tercapai & Ya & $\begin{array}{l}\text { Memantau pencatatan keuangan dan } \\
\text { pembukuan yang para peserta sudah } \\
\text { terapkan, setelah itu, penulis dan tim } \\
\text { memberikan masukan jika ada yang } \\
\text { kurang tepat. }\end{array}$ \\
\hline $\begin{array}{l}\text { Peserta mampu } \\
\text { memahami dasar } \\
\text { ilmu Perencanaan } \\
\text { Bisnis }\end{array}$ & Tercapai & Ya & $\begin{array}{l}\text { Memantau perkembangan bisns } \\
\text { secara keseluruhan yang para } \\
\text { peserta sudah terapkan, setelah itu, } \\
\text { penulis dan tim memberikan } \\
\text { masukan jika ada yang kurang tepat. }\end{array}$ \\
\hline
\end{tabular}

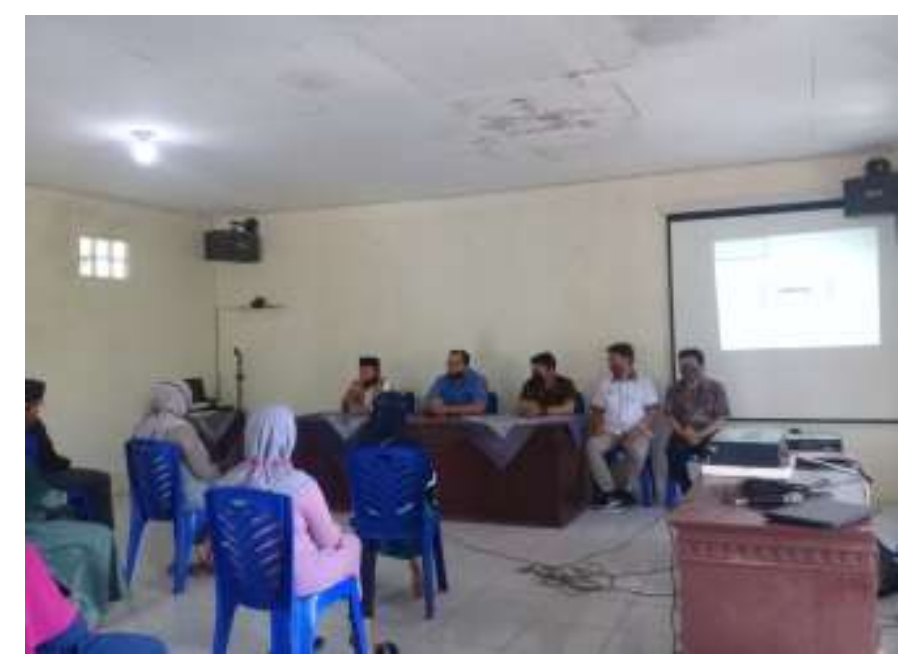

Gambar 1. Pengenalan Tim Pengabdian oleh Kepala Desa Balesari kepada Para Peserta Pelatihan

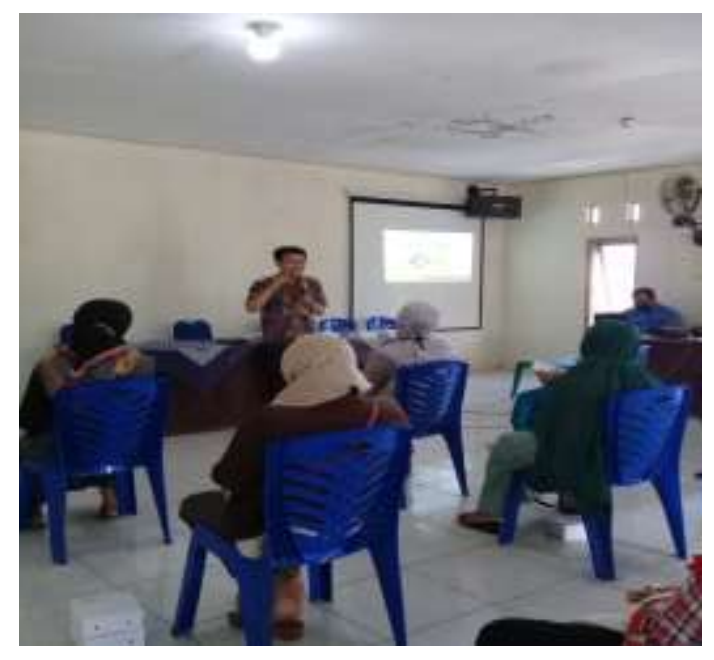

Gambar 2. Penyampaian materi Pemasaran 

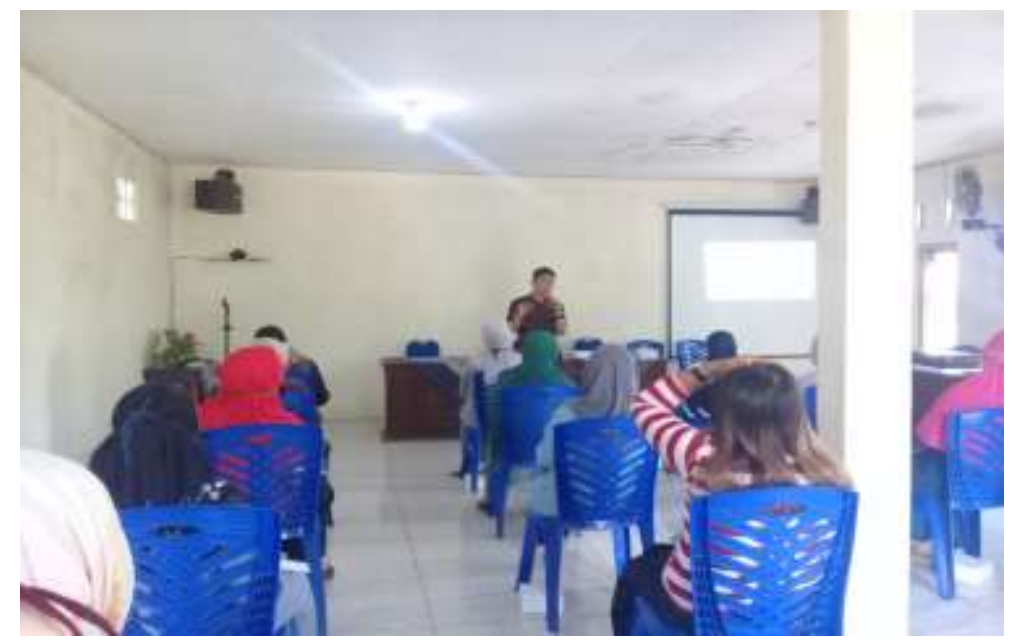

Gambar 3. Penyampaian materi Perencanaan Bisnis

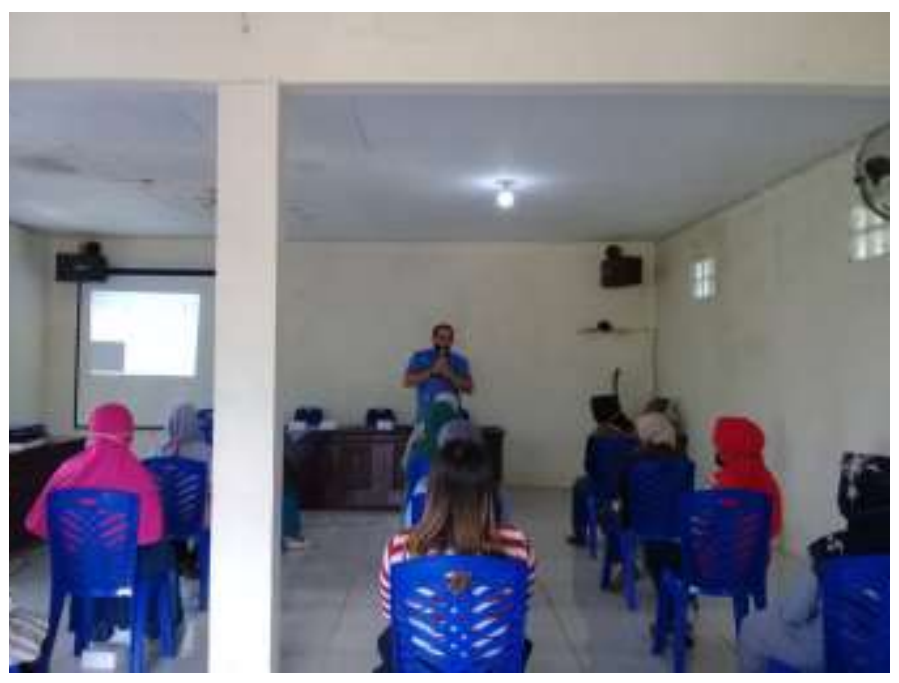

Gambar 4. Penyampaian materi Manajemen Keuangan

\section{KESIMPULAN}

Kesimpulan yang dapat diambil dari kegiatan program kemitraan kepada masyarakat ini adalah hasil yang menunjukkan bahwa kegiatan pengabdian masyarakat yang terprogram dapat meningkatkan pengetahuan dan keterampilan pelaku UMKM di Desa Balesari. Tim pengabdian berusaha menargetkan upaya pelaksanaan penyuluhan mengenai pelatihan, manajemen, dan keterampilan dalam membuat business plan (perencanaan bisnis) maupun pembuatan laporan keuangan bagi pelaku UMKM di Desa Balesari. Program ini dibuat dengan mempertimbangkan tujuan agar pelaku UMKM mampu mengelola usaha dan keuangan menjadi lebih terarah secara terperinci sehingga dapat menunjang perkembangan dan kemajuan usahanya.

Fenomena menarik dilapangan adalah para pelaku UMKM di Desa Balesari belum melakukan sistem pembukuan laporan keuangan yang sesuai dengan standar akuntansi. Alasannya yaitu karena tidak pernah mendapat pelatihan, sehingga mereka belum memiliki pengetahuan dan keterampilan di bidang laporan keuangan UMKM. Setelah adanya pengabdian ini, UMKM di Desa Balesari sudah berusaha membuat pembukuan laporan keuangan UMKM dengan baik sesuai dengan standar akuntansi untuk laporan keuangan. 
Agar dapat terus berkembang maju UMKM Balesari harus lebih sering mengikuti seminar, workshop dan pelatihan mengenai manajemen dan penyusunan laporan keuangan yang baik sehingga dapat meningkatkan keterampilan dalam manajemen bisnis, akurasi modal, beban operasional dan laba secara akurat. Masih diperlukan juga pendampingan lebih lanjut utamanya dalam rangka pembukuan laporan keuangan pada UMKM, terutama secara sistem menggunakan aplikasi dan pendampingan cara pembayaran pajak. Khususnya mengenai bimbingan teknis. Motivasi lebih mendalam juga diperlukan untuk terus memberikan sosialisasi mengenai pentingnya sistem pembukuan yang baik dan benar terhadap para pemilik UMKM, agar pemilik UMKM di Desa Balesari tetap terus melakukan pembukuan laporan keuangan sesuai dengan SAK EMKM (Standar Akuntansi Keuangan Entitas Mikro Kecil Menengah), dan mampu merekonstruksi dari pembukuan manual ke pembukuan secara sistem menggunakan aplikasi/software laporan keuangan yang khusus diperuntukkan untuk UMKM.

\section{UCAPAN TERIMA KASIH}

Penulis mengucapkan terima kasih kepada LPPMP Universitas Tidar yang telah memberi dukungan financial terhadap pengabdian ini.

\section{DAFTAR PUSTAKA}

Bhuvaneswari, K., Geethalakshmi, V., Lakshmanan, A., Srinivasan, R., \& Sekhar, N. U. (2013). The impact of El Nino/ Southern Oscillation on hydrology and rice productivity in the Cauvery Basin, India: Application of the soil and water assessment tool. Weather and Climate Extremes, 2, 39-47.

Handayani, SB (2014). "Model Pemasaran Era New Wave Marketing". Jurnal Ekonomi Manajemen dan Akuntansi No. 36 / Th. XXI / April 2014.

Hanna Fitriyati (2013). "Strategi Pemberdayaan Usaha Mikro, Kecil dan Menengah di Indonesia". Jurnal Ekonomi IAIN. Mataram.

Heni (2012). "Analisis SWOT Dan Promosi Kerajinan Bambu Desa Wisata Brajan Kabupaten Sleman Yogyakarta". Jurnal AKPAR BSI. Yogyakarta.

Kurniawan, et.al, (2013). Strategi Pengembangan Agribisnis, Jurnal Manajemen Agribisnis, Volume 1, No 2, Halaman 55. Oktober 2013. ISSN: 2355-0759

LPPM-PMP Universitas Tidar 2020, Panduan Pelaksanaan Pengabdian Kepada Masyarakat Universitas Tidar, Untidar, Magelang.

Masnita, Y., Khomsiyah, \& Hermien Triyowati. (2020). Peningkatan Daya Saing Usaha Mikro (UMi) Melalui Keuangan Inklusi. Dinamisia : Jurnal Pengabdian Kepada Masyarakat, 4 (2), 255-262.

Mohideen. P. Suresh. Akbar. M. 2010. Research and Markets: Micro, Small and Medium Enterprises (MSMES) in the Indian Economy: Business Development Strategies.

Nirat Soodsang, PhD, 2013. Bamboo Basketry Design Development bases on Thai Wisdom Preservation. International Jurnal of Business and Social Science, Vol 6, No 7, Halaman 140141, ISSN 2219-1933

Rajaman, Kumaram (2014). Business Endeavours In Savaoury Snack Industry Old Chang Kee, International Journal of Business and Social science, Vol. 5, No. 6(1), halaman 171-177, Center for Promotion Ideas, USA

Supriyanto. 2005. "Pemberdayaan Usaha Mikro, Kecil, Dan Menengah (UMKM) Sebagai Salah Satu Upaya Penanggulangan Kemsikinan". Jurnal Ekonomi dan Pendidikan, Volume 2 Nomor 1, April 2006 Universitas Negeri Yogyakarta. Yogyakarta.

Wahyuning, Putri. 2014. "Peningkatan Kinerja Usaha Kecil dan Menengah (UKM) Kluster Kerajinan Di Kota Depok Menggunakan The House Model". Jurnal Manajemen dan Organisasi Vol V, No 2, Agustus 2014. Institut Pertanian Bogor.Bogor. 